HUNTER, Wendy. Eroding Military Influence in Brazil. Politicians against Soldiers. Chapel Hill and London : University of North Carolina Press, 1997 (ISBN 0807846201; paperback: U\$ 18,95).

\title{
INFLUÊNCIA MILITAR NA ATUAL POLÍTICA BRASILEIRA: EROSÃO OU RETIRADA?
}

\author{
Francisco César Alves Ferraz \\ Universidade Estadual de Londrina
}

Na historiografia política recente do Brasil, o debate sobre a transição do regime autoritário-militar (19641985) para os governos democráticos já produziu volumosa bibliografia documental (especialmente depoimentos orais) e analítica. Embora a variedade de interpretações seja considerável, alguns pontos parecem, no entanto, obter a concordância geral dos estudiosos. Um deles é o caráter predominantemente militar da condução das fases iniciais da distensão e transição, controlado pela cúpula presidencial (Geisel e Golbery à frente), deixando relativamente poucos espaços para as lideranças civis. Outro ponto consensual é a manutenção das prerrogativas institucionais de influência militar na política, mesmo nos governos civis do período pósautoritário. Alguns autores chegaram, inclusive, a afirmar a permanência da tutela militar sobre a política brasileira ${ }^{1}$.

O livro de Wendy Hunter - baseado em tese de doutorado apresentada na Universidade da California em 1992 e atualizado com dados e análises até o início do primeiro mandato de Fernando Henrique Cardoso coloca em xeque essa interpretação hegemônica. Para a autora, ao invés do reforço e/ou manutenção, houve sim erosão do poder de influência militar na política, principalmente a partir do governo de Fernando Collor de Mello. Apesar de força institucional dos militares (e a posse da ultima ratio, que seriam as armas), suas propostas e pretensões teriam sido crescentemente contestadas pelos políticos do Legislativo e do Executivo.

Como isso pôde acontecer? Segundo Hunter, a competição eleitoral criou incentivos aos políticos para reduzir o poder dos militares, de modo a ampliar seu raio de ação política e eleitoral. Na configuração políticopartidária brasileira, com seus laços seculares de clientelismo e um patronato por categorias em franca consolidação (industriais, ruralistas, religiosos, categorias de trabalhadores, grupos regionais), os políticos esforçar-se-iam para contestar o poder militar, mesmo que apenas retoricamente ${ }^{2}$. Dessa maneira, seja por motivos particulares (clientelismo, redes de poder pessoal e regional), seja por motivos retórico-pragmáticos (quando mesmo a direita mais conservadora adota discursos de apelo populista para se eleger), o livre jogo democrático semearia o conflito entre os interesses dos políticos civis e os dos militares. Por sua vez, a vitória eleitoral ofereceria a legitimidade necessária para desafiar os militares. Segundo esse raciocínio, a ausência de tal legitimidade fez de Sarney refém da tutela militar, o oposto de Collor, que lastreado pelos milhões de votos obtidos em 1989, desafiou e refreou o poder fardado (p. 12).

Depois de descrever o fortalecimento do poder político militar e a manutenção de grande parte de suas prerrogativas até o fim do governo Sarney, a autora escolheu quatro instâncias em que a competição eleitoral

\footnotetext{
1 É, principalmente, os casos de STEPAN, 1988 e ZAVERUCHA, 1994. Em ambos, a perspectiva é a das relações dos militares com o governo de José Sarney e nos debates da Assembléia Nacional Constituinte. O livro de O LIVEIRA, 1994 que aborda também os governos de Collor de Mello e de Itamar Franco, também se refere à "tutela", mas restringe 0 fenômeno ao período Sarney. Vale dizer que muitos analistas da política latino-americana recente ainda insistem na permanência da influênca militar e nos limites impostos à consolidação democrática (cf. RUHL, 1998).

2 É no mínimo curioso que próceres civis do regime militar, como Antonio Carlos Magalhães, denunciem atualmente inimigos de ocasião como "filhotes da ditadura". Com efeito, mostrar-se "amigo dos militares" nunca rendeu muitos votos, ainda mais no período pós-autoritário..
} 
teria determinado a erosão da influência militar: as estruturas institucionais do Estado brasileiro, os direitos trabalhistas, a política orçamentária e a definição das políticas para a Amazônia. Em todas elas, de uma maneira ou de outra, os políticos civis tiveram relativo sucesso na ampliação de seus espaços de ação e decisão, em detrimento daqueles ocupados pelos militares.

Por fim, após reforçar seu argumento principal com um rápido estudo comparativo dos casos da transição chilena, argentina e peruana, Hunter conclui que, diferentemente do que afirma a literatura histórico-sociológica das transições, a institucionalização das rotinas democráticas produziu um impacto decisivo para a diminuição do poder político militar, o que pode ser percebido também nos outros países sul-americanos estudados 3 . Houve, assim, uma notável redução da influência militar na política e, sua contrapartida, a expansão da capacidade de formulação e decisão dos assuntos nacionais pelos políticos civis (p. 140).

Hunter adverte, contudo, que tal redução da influência militar não significa ainda o controle democrático da instituição militar, pois é preciso que os políticos civis tomem para si a responsabilidade de debater e deliberar sobre as questões que envolvam o uso das Forças Armadas. Essa advertência, porém, não invalida sua conclusão: o declínio da influência militar é a tendência mais persistente e consolidada das relações entre os militares e civis no Brasil (p. 173).

Pela originalidade e coerência de sua hipótese principal, pode-se incluir o livro de Hunter como leitura essencial para o estudo da transição para a democracia no Brasil. No entanto, embora a afirmação do declínio atual da influência militar seja algo inquestionável, é duvidoso creditá-lo quase exclusivamente ao papel preponderante dos políticos civis, em busca de vantagens eleitorais. Se sua abordagem das "escolhas racionais" dos políticos brasileiros é brilhante, lamentavelmente sua compreensão das motivações dos militares brasileiros decepciona. Talvez dever-se-ia perguntar se os vários grupos que compõem as Forças Armadas brasileiras estariam mesmo dispostos a enfrentar os políticos e a opinião pública, a nova realidade estratégica mundial e seus próprios dilemas internos, para a manutenção da influência tutelar na política brasileira. Todas as pesquisas a partir dos depoimentos dos personagens militares do regime autoritário e mesmo daqueles que ocuparam postos de destaque nos governos civis, insistem na inviabilidade política e na inconveniência institucional de insistir na proeminência militar nos dias atuais (cf. D'ARAUJO, SOARES e CASTRO, 1995; D'ARAUJO e CASTRO, 1997; e CONTREIRAS, 1998).

Além de conferir importância secundária às motivações militares para o (não) envolvimento na política atual, Hunter não explica porque os políticos civis deixaram de recorrer aos quartéis. As rotinas democráticoeleitorais não explicam tudo. Afinal, práticas eleitoreiras clientelísticas são anteriores à República, e estímulos eleitorais para arrebanhar cargos, verbas e espaços políticos nunca haviam antes motivado os políticos a desafiar os soldados. Muito pelo contrário, a classe política civil — à direita ou mesmo à esquerda, é importante lembrar - sempre enxergou as Forças Armadas de maneira instrumental, como um aliado imprescindível ou um inimigo temível. Tampouco a legitimidade eleitoral justifica tal mudança, pois ao longo deste século, presidentes como Vargas, Kubitschek, Jânio e Goulart foram referendados em eleições e mesmo assim foram desafiados ou mesmo derrubados pelo poder militar, para o gáudio das "vivandeiras dos bivaques", na precisa definição do general Castello Branco para as romarias de políticos aos quartéis, desejosos de ações militares para reversão de resultados das urnas.

A polarização das eleições presidenciais de 1989 e o flagrante alívio das classes conservadoras pelas derrotas eleitorais da esquerda e pela instauração da ordem neoliberal podem fornecer pistas preciosas de que, somente após a consolidação das alianças conservadoras, os políticos tiraram o endereço da caserna de sua agenda.

Por sua vez, muitos militares brasileiros guardam ressentimentos amargos da intervenção direta na política: para esses oficiais, a instituição armada ficará para a história por ter feito o "trabalho sujo", enquanto o empresariado e os políticos cresciam em fortuna e poder, além de posarem como paladinos da democracia.

Mudaram os políticos ou mudaram os militares? Ambos mudaram. O fim da "guerra fria" e a consolidação das estruturas neoliberais no Brasil e em seus vizinhos obrigaram civis e militares a repensarem suas idéias e

\footnotetext{
3 A exceção a essa tendência seria o caso peruano, onde houve um retrocesso provocado pela incapacidade dos governos anteriores a Fujimori em resolver o problema da guerrilha e da crise econômica.
} 
suas práticas. Além disso, houve a ascensão natural de uma geração de oficiais mais "profissionais"4, conscientes das ameaças do germe da política na unidade institucional das Forças Armadas. É mais fácil, assim, entender porque os militares estariam dispostos a ceder espaços que não mais reconheceriam como seus, tais como a definição das relações de trabalho ou os cargos civis nos ministérios e nas empresas estatais. E também compreender porque os civis não encontraram obstáculos tão intransponíveis para estabelecer sua hegemonia.

Não seria possível então sugerir que, ao invés de uma erosão de poder, provocada pelas chuvas da democracia competitiva, foi desencadeada uma retirada militar, face à combinação das investidas bem sucedidas dos políticos civis em suas possessões e prerrogativas políticas, das dificuldades e perigos da cizânia no seio da tropa e do peso de uma auto-estima institucional seriamente comprometida pelo passado recente? Esta é uma questão que somente mais e mais pesquisas poderão esclarecer, e sobre a qual este livro oferece uma contribuição importante 5 .

Assim, apesar dos problemas levantados, o livro de Wendy Hunter é uma obra seminal para os estudos futuros da história política recente do Brasil. Trata-se de um trabalho que já merecia tradução para o português, possibilitando acesso mais amplo aos interessados sobre o tema. Assim, por seus méritos e pelos problemas que pode suscitar, o livro de Hunter torna-se referência obrigatória no estudo dessa fase de transição política no Brasil.

Recebido para publicação em agosto de 1999.

Francisco César Alves Ferraz (fcaf64@ hotmail.com) é Professor-Assistente do Departamento de História da Universidade Estadual de Londrina (UEL) e doutorando em História Social na Universidade de São Paulo (USP).

\section{REFERÊNCIASBIBLIOGRÁFICAS}

CONTREIRAS, H. 1998. Militares: confissões. Histórias secretas do Brasil. Rio de Janeiro: Mauad.

D’ARAUJO, M. C.; SOARES, G. A. D., \& CASTRO, C. (orgs.). 1995. A volta aos quartéis: a memória militar sobre a abertura. Rio de Janeiro: Relume-Dumará.

D’ARAUJO, M. C. \& CASTRO, C. (orgs.). 1997. Ernesto Geisel. Rio de Janeiro: Fundação Getúlio Vargas.

NUNN, F. M. 1995. The South American Military and (Re)Democratization: Professional Thought and SelfPerception. Journal of Interamerican Studies and World Affairs, Miami, vol. 37, n. 2, p. 1-56, Summer.

OLIVEIRA, E. R. de. 1994. De Geisel a Collor: Forças Armadas, transição e democracia. Campinas: Papirus.

RUHL, J. M. 1998. Changing Civil-Military Relations in Latin America. Latin American Research Review, Albuquerque, vol. 33, n. 3, p. 257-269.

STEPAN, A. 1988. Rethinking Military Politics. Brazil and the Southern Cone. Princeton: Princeton University Press.

\footnotetext{
4 "Profissional" aqui não quer dizer "apolítico", pois, a rigor, inexiste apoliticismo em uma instituição como a militar, pertencente ao Estado nacional e que monopoliza os meios de coerção política, que é a força das armas. 0 significado aqui sugerido é o de consciência e respeito às instituições democráticas e constitucionais. Sobre a crise de identidade militar, os impasses da nova ordem estratégica pós-guerra fria e a ascensão de oficiais mais profissionais e menos identificados com 0 regime militar, cf. TOLLEFSO N, 1998; D 'ARAUJO, SOARES e CASTRO, 1995; e OLIVEIRA, 1994. A revista A Defes Naainal constitui uma excelente fonte documental sobre o debate interno a respeito dos rumos políticos e profissionais das Forças Armadas brasileiras.

5 A perspectiva de uma retirada da cena política, ao invés de uma derrota pura e simples para os civis, já havia sido sugerida por NUNN (1995, p. 28), em seu estudo sobre a percepção política e profissional dos militares sul-americanos face à onda democratizante em seus países.
} 
TOLLEFSON, S. D. 1998. National Security. In: HUDSON, R. A. (ed.). Brazil: a Country Study. 5th ed. Washington, D.C.: Federal Research Division/Library of Congress.

ZAVERUCHA, J. 1994. Rumor de sabres. Tutela civil ou controle militar? Estudo comparativo das transições democráticas no Brasil, Argentina e Espanha. São Paulo: Ática. 